\title{
Learning to teach optics through experiments and demonstrations
}

Jesús Lancis, Mercedes Fernández-Alonso, Lluis Martínez-León, Enrique Tajahuerce-Romera, Gladis Mínguez-Vega

Jesús Lancis, Mercedes Fernández-Alonso, Lluis Martínez-León, Enrique Tajahuerce-Romera, Gladis Mínguez-Vega, "Learning to teach optics through experiments and demonstrations," Proc. SPIE 9289, 12th Education and Training in Optics and Photonics Conference, 92891C (17 July 2014); doi: $10.1117 / 12.2070521$

SPIE Event: 12th Education and Training in Optics and Photonics Conference, 2013, Porto, Portugal 


\title{
Learning to teach Optics through experiments and demonstrations
}

\author{
Jesús Lancis, Mercedes Fernández-Alonso, Lluís Martínez-León,* \\ Enrique Tajahuerce, Gladys Mínguez-Vega \\ Physics Department / Institute of New Imaging Technologies, Universitat Jaume I, \\ Castelló de la Plana, Spain
}

\begin{abstract}
We have applied an active methodology to pre-service teacher training courses and to active teacher workshops on Optics. As a practical resource, a set of demonstrations has been used to learn how to perform classroom demonstrations. The set includes experiments about polarization and birefringence, optical information transmission, diffraction, fluorescence or scattering. It had been prepared for Science popularization activities and has been employed in several settings with a variety of audiences.

In the teacher training sessions, simple but clarifying experiments have been performed by all the participants. Moreover, in these workshops, devices or basic set-ups, like the ones included in our demonstration set, have been built. The practical approach has allowed the enthusiastic sharing of teaching and learning experiences among the workshop participants. We believe that such an active orientation in teacher training courses promotes the active and collaborative teaching and learning of Optics in different levels of Education.
\end{abstract}

Keywords: Teacher preparation, Participatory teaching and learning, Experiments on Optics.

\section{INTRODUCTION}

According to a commonplace belief, periodic reforms in the Spanish Education System, involving a new Primary and Secondary Education Act, occur each time that a new government has taken office. Besides severe budget restrictions, the system is now starting the most recent reform so far. ${ }^{1}$ Concerning Higher Education, Bologna process ${ }^{2}$ has transformed teaching methods and structures in the last five or four years. ${ }^{3,4}$ The academic staff has been encouraged to move towards a new paradigm: a methodology more focused on the student's autonomous learning rather than in the role of the teacher. Moreover, the stress on competencies (the skills the students have to learn, practice and be able to reproduce in varying and complex situations), the implementation of continuous assessment, or the intention of thoroughly planning the student's workload, are some of the intended features of the new model. As a third factor of change, concerning this time Spanish Teacher Training, not only a bachelor's degree, typically in the area one wants to teach, is needed in order to be qualified to teach in secondary schools. A master level degree, a full-time program, approximately 12 months long, is now compulsory (since 2008). ${ }^{5}$

The authors of this communication, academic staff at the Universitat Jaume I, Castelló de la Plana (Spain), develop their research tasks in the Photonics Research Group (GROC.UJI), but participate as well in the Innovative Teaching Group Physics Education and Popularization team. The members of the team perform regular activities related to Science popularization, develop innovative projects in their undergraduate and graduate courses and are involved in teacher training courses and workshops. Aware of the changing environment in the different levels of Education and in teacher preparation, as depicted in the previous paragraph, we would like to report the active methodology we have applied in pre-service teacher training courses (in the Teacher Training Master) and in active teacher workshops on Optics. We have taken part, in the role of conductors, in some active teacher workshops, often organized by the Scientific Area in the formation and resource center for primary and secondary school teachers in Castelló (CEFIRE, Centre de formació, innovació i recursos educatius). ${ }^{6}$ Both organizers and participant teachers are creative and very dynamic professionals. In the following sections, we describe some of the activities performed in the courses and workshops, and how they have served to share the learning and teaching background of participants and conductors.

*lluis.martinez@uji.es

12th Education and Training in Optics and Photonics Conference, edited by

Manuel F. P. C. Martins Costa, Mourad Zghal, Proc. of SPIE Vol. 9289, 92891C

(C) 2014 SPIE, OSA, IEEE, ICO · doi: 10.1117/12.2070521

Proc. of SPIE Vol. 9289 92891C-1 


\section{ACTIVITIES ON OPTICS IN TEACHER WORKSHOPS}

In both active teacher and initial teacher training workshops, we have used a set of demonstrations on Optics that had been prepared for Science popularization activities. The set has been employed in several settings with a variety of audiences, also with the most general audience in outreach activities, in undergraduate and postgraduate Physics courses, and with secondary school students. The complete reference list including other experiments and activities has been reported elsewhere. ${ }^{7}$

For promoting critical thinking and fostering motivated and independent teachers and learners, we have developed active and collaborative sessions. Although some classroom demonstrations have been performed, most of the time has been devoted to the design, construction and test of some devices or basic set-ups, and to the development of simple but striking experiments, that could be easily undertaken in secondary school courses.

The first activity reported here is related to diffraction. Apart from gaining insight into this phenomenon, one specific goal is estimating the spacing of CD or DVD tracks. ${ }^{8}$ As the tiny periodic structure of CD or DVD acts as a diffraction grating, the measurement of the length between orders of diffraction and the distance between the screen and the object can provide the period of the tracks. For a transmission experiment, first the reflecting layers of these discs have to be peeled off. Next, with a laser pointer, the two length measurements may be repeated several times as a function of the separation between the object and the screen, to get rid of statistical errors and obtain an accurate result. Then, simple calculations give the estimated data corresponding to CDs or DVDs.
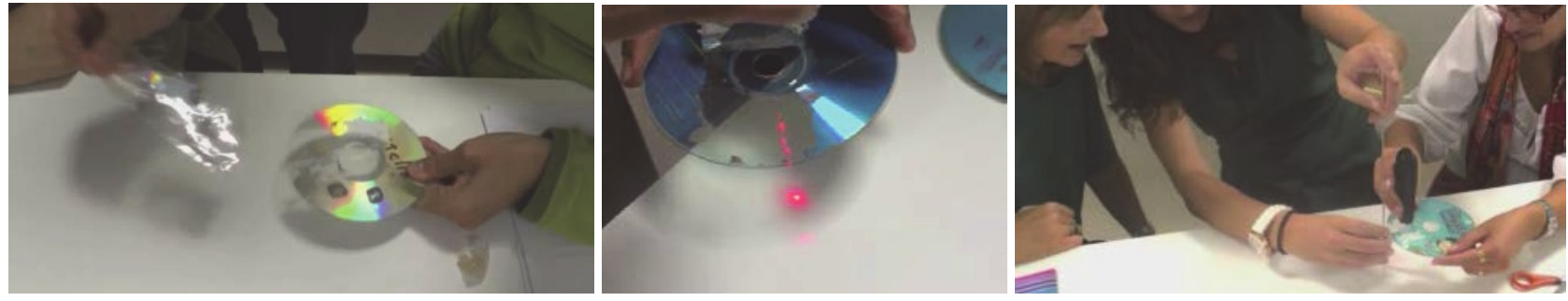

Figure 1. Participants in a teacher training workshop peel off the reflecting layer, study the diffraction phenomenon and perform the measurements needed in order to calculate the grating period.

If participants are provided with undistinguished discs, one final task may consist in identifying their kind of digital media. A second activity linked to diffraction is proposed in an exciting video by Dr. Andrew Steele, from the University of Oxford. ${ }^{9}$ The video nicely explains how to make a spectrometer in a very simple way, using a cereal box and a CD. We have introduced some improvements in the procedure, concerning the slit. The participants in these activities were invited to bring with them old CDs and one or two cereal boxes. Once the cereal box spectrometer has been built, the next activity is checking the spectra of different light sources. When bringing the activity to a secondary school classroom, the warning of avoiding the use of the home-made spectrometer with a relative powerful source, such as laser pointer, is truly worth. Figure 2 presents one of the workshop-made spectrometers, and the spectra of a conventional light bulb or an efficient one.
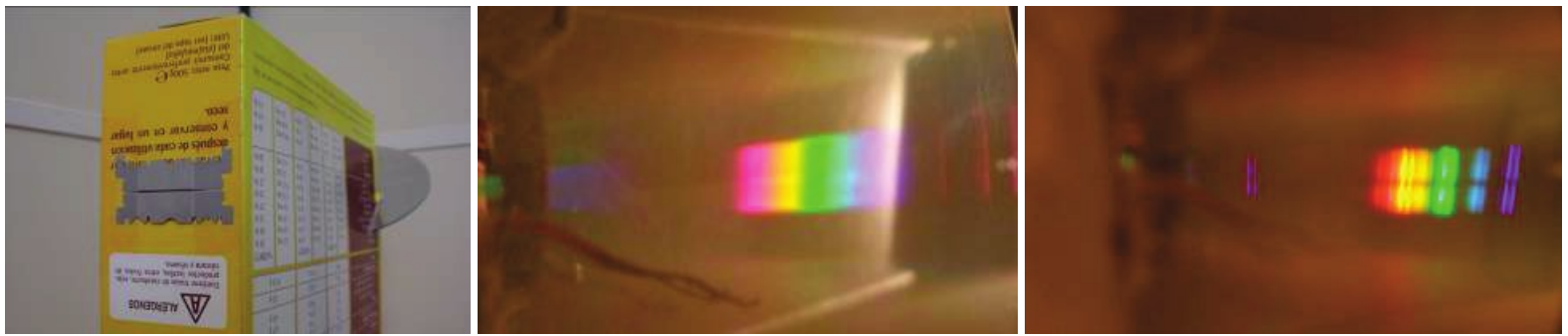

Figure 2. Workshop-made spectrometer (left), built following instructions from Dr. Andrew Steele (University of Oxford), and spectra of conventional (center) or efficient (right) light bulbs.

Figure 3 show two pictures of an active-teacher workshop, building a cereal-box spectrometer and observing different light sources spectra. 

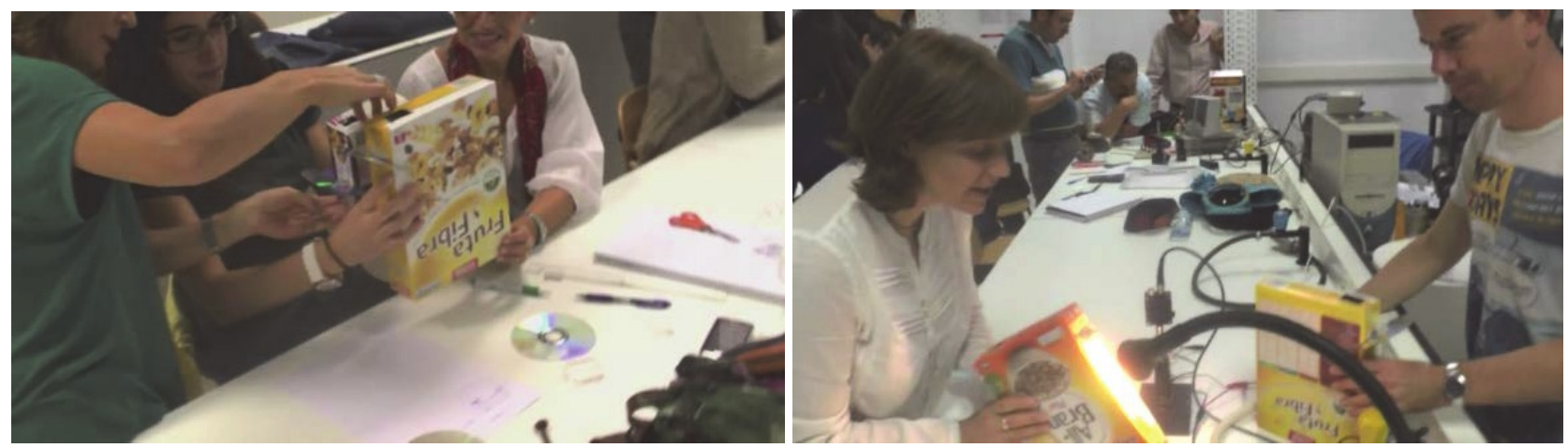

Figure 3. Teachers building their own cereal-box spectrometer, and using it to observe different light sources spectra.

A third experiment related to diffraction involves the light pattern created when illuminating a blood sample with an intense laser pointer. This figure, with a bright central spot, the Airy disk, corresponds to the diffraction pattern created by a circular aperture, or a set of these apertures like the red blood cells of a blood sample. Again, the measurement of two distances, the length between the object and the screen and the radius of the first dimmer ring surrounding the Airy disk, provides an estimation of the characteristic length in the sample, the blood cell diameter. We have presented this experiment as a demonstration, but the preparation of the sample could be also of great interest for life Science teachers or students.

Another experiment carried out in our training courses tackles the verification of total internal reflection. A guiding light application is exemplified with a tank of water and an intense laser pointer. The dependence on the incidence angle is one of the properties of total internal reflection that can be studied. Figure 4 illustrates the Airy disk generated by diffraction by a blood sample and the water optical waveguide illustrating the total internal reflection phenomenon.
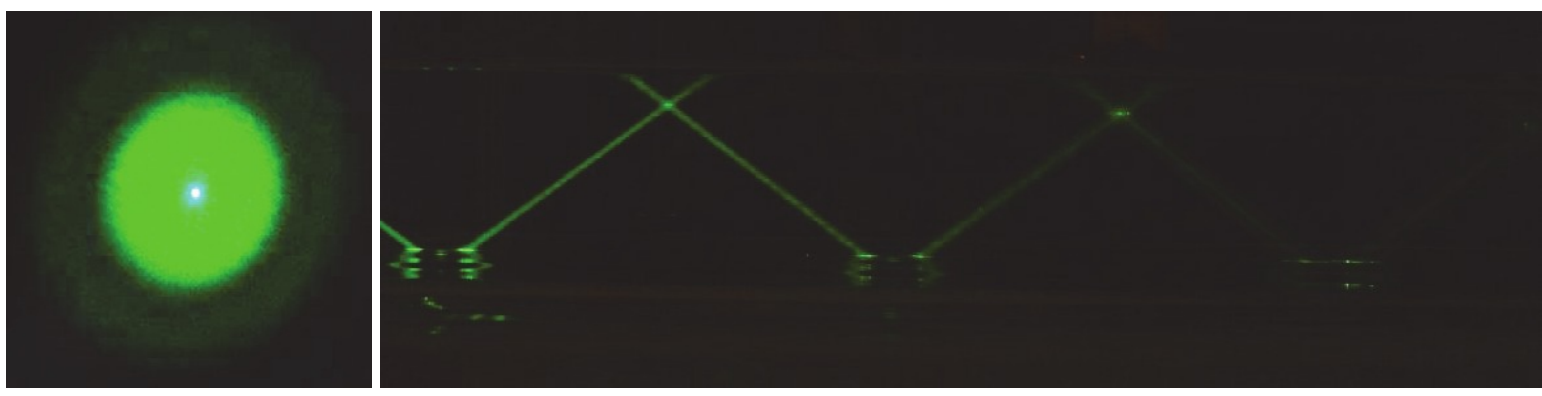

Figure 4. Airy disk pattern created with a laser and a blood sample (left) and total internal reflection in a water tank (right).

We have also introduced polarization concepts through practical demonstrations. A polariscope is an instrument that can display the properties of polarized light interacting with optically transparent media. It consists of two crossed polarizers in the opposite sides of a cardboard box, and can be built with two parts of a polarizer sheet. Thanks to the polariscope, the mechanical tensions in a CD plastic case, in the glasses of participants or in a plastic water bottle can be visualized, as shown in Figure 5. Retarder plates are illustrated by introducing a simple acetate transparency at a $45^{\circ}$ angle to the base of the polariscope. In Figure 5 (center), the background is not longer opaque, thanks to the birefringence properties of the transparency, similar to those of a half-wave plate.

The Tyndall-Rayleigh phenomenon, which explains the red color of twilight, is reproduced using a small amount of milk diluted in a water tank. The slightly reddish colour of the light reaching the end of the tank is perceived. ${ }^{10}$ By using a polarizer, the polarization features of scattered light and the lack of a preferred polarization axis in the non-scattered light are observed, as shown in Figure 5 (right).

Both in initial teacher training and in active-teacher workshops, the practical approach has allowed the enthusiastic sharing of teaching and learning experiences among the participants. Teachers have enjoyed the activities, have told the other participants their own background or their future ideas in this kind of practical work, and hopefully have been highly motivated to apply similar active and collaborative methodologies in their daily teaching practice. 

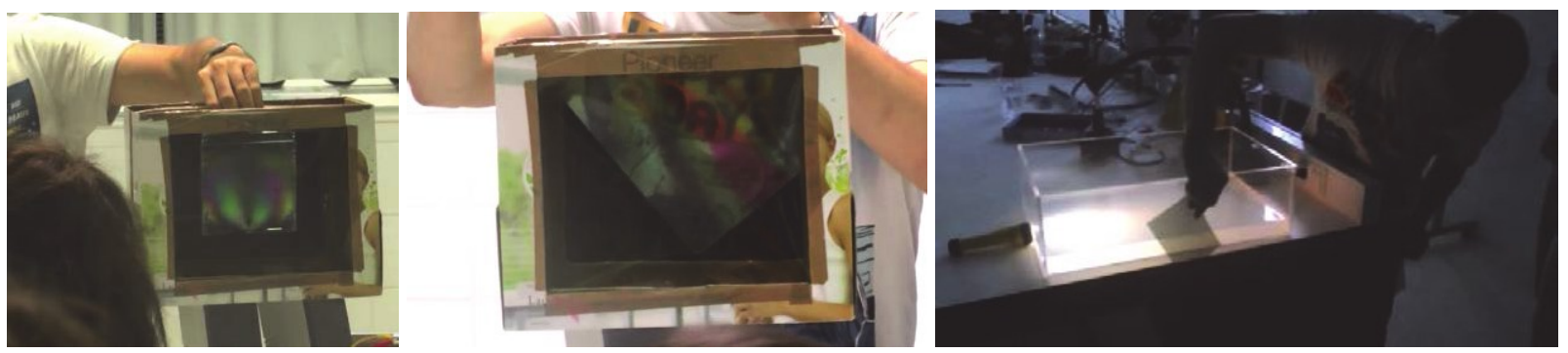

Figure 5. Polarization experiments: visualization of the mechanical tensions in a CD plastic case with a polariscope (left), illustration of the birefringence properties of an acetate transparency acting as a half-wave plate (center), and study of the polarization of scattered light (right).

\section{CONCLUSIONS}

We have presented the collaborative methodology applied in pre-service teacher training courses and in active teacher workshops on Optics. All the participants have built and tested some optical devices or basic set-ups. Also, simple but striking experiments, which could be easily undertaken in secondary school courses, have been developed.

The practical approach has allowed the enthusiastic sharing of teaching and learning experiences among the participants. We believe that such an active orientation in teacher training courses promotes the active and collaborative teaching and learning of Optics in different levels of Education, promotes critical thinking and fosters motivated and independent teachers and learners.

\section{ACKOWLEDGEMENTS}

The authors, who belong to the Innovative Teaching Group Physics Education and Popularization team, acknowledge support from Unitat de Suport Educatiu at Universitat Jaume I. We also gratefully acknowledge Prof. Amparo PonsMartí (Universitat de València, Spain) for counselling and encouragement. Some of the pictures of this communication were taken in an active teacher workshop by Dr. Sergio Mestre Froissard (CEFIRE de Castelló de la Plana) who has kindly provided them.

\section{REFERENCES}

[1] Blitzer, J., "War of the Words," The New York Times, 18 December 2012, $<$ http://latitude.blogs.nytimes.com/2012/12/18/war-of-the-words/> (10 June 2013).

[2] "The Bologna Process - Towards the European Higher Education Area", European Comission, < http://ec.europa.eu/education/higher-education/bologna_en.htm> (10 June 2013).

[3] Martínez-León, Ll., Darraud, C., Cosset, F., Bessaudou, A., Brevier, J., Fernández-Alonso, M., Mínguez-Vega, G., Tajahuerce, E., Lancis, J., and Climent, V., "Strategies for improving Science Education on both sides of Pyrenees," INTED2010 Proceedings, 4949-4955 (2010).

[4] Martínez-León, Ll., Fernández-Alonso, M., Lancis, J., Tajahuerce, E., Mínguez-Vega, G., and Alós-Valls, H., "Driving an Introductory Physics course on the road to Bologna: Bologna, just a first stage of the journey or the final destination?," INTED2013 Proceedings, 684-687 (2013).

[5] "Initial Teacher Training for Secondary Education", Spanish Ministry of Education, Culture and Sports, $<$ http://www.mecd.gob.es/educacion-mecd/en/areas-educacion/profesorado/formacion/formacioninicial/secundaria.html> (10 June 2013).

[6] "Scientific Area blog", CEFIRE de Castelló, <http://ambitcientific.blogspot.com.es/> (10 June 2013).

[7] Martínez-León, Ll., Fernández-Alonso, M., Lancis, J., Tajahuerce, E., Mínguez-Vega, G., Alós-Valls, H., Durán-Bosch, V., Climent, V., Sanchis-Ferriol, N., Pérez-Vizcaíno, J., Clemente-Pesudo, P., and Mendoza- 
Yero, O., "Focusing on people's curiosity: Science popularization through experiments and demonstrations on Optics for a variety of audiences," INTED2013 Proceedings, 678-683 (2013).

[8] Balachandran, R., Porter-Davis, K., "Using CDs and DVDs as diffraction gratings", $<\mathrm{http}$ //www.nnin.org/sites/default/files/files/Karen_Rama_USING_CDs_AND_DVDs_AS_DIFFRACTION_ GRATINGS_0.pdf> (10 June 2013).

[9] Steele, A., "Make your own CD spectrometer," Department of Physics, University of Oxford $<$ http://www2.physics.ox.ac.uk/lab-camera-action/make-your-own-cd-spectrometer> (10 June 2013).

[10] "Photon and Photon 2: Explorations in Optics," New England Board of Higher Education $<$ http://www.nebhe.org/wp-content/uploads/ExplorationInOptics-2010.pdf > (10 June 2013). 